\title{
Determination of Short-Chain Fatty Acids in Raw Milk Using a Microbial Sensor and the Relationship with Milk Quality
}

\author{
Hiroyuki Ukeda, Yoshihiro Fujta, Masayoshi Sawamura and Hirozo Kusunose \\ Department of Bioresources Science, Faculty of Agriculture, Kochi University, \\ Monobe, Nankoku 783, Japan
}

Keywords Microbial sensor, short-chain fatty acid, microbial count, milk quality

The short-chain fatty acids $\left(\mathrm{C}_{4: 0}-\mathrm{C}_{12: 0}\right)$ in milk are the major cause of rancid flavor development. Therefore, the determination of short-chain fatty acids is an important criterion of raw-milk quality.,2 A microbial sensor for the rapid analysis of short-chain fatty acids levels was previously developed based on the bacteria Arthrobacter nicotiana, and was demonstrated to have a selective response. ${ }^{3,4}$

The present study was conducted in order to determine the milk quality, such as the microbial count and spontaneous lipolysis, using a microbial sensor, and to assess its possible application for the routine analysis of milk quality. The preparation conditions of the microbial membrane were also re-examined.

\section{Experimental}

\section{Microbial membrane}

Arthrobacter nicotiana (DSM No. 6707) was cultivated in a medium containing $0.3 \%$ yeast extract, $0.5 \%$ peptone, $0.5 \% \mathrm{~K}_{2} \mathrm{HPO}_{4}, 0.5 \% \mathrm{KH}_{2} \mathrm{PO}_{4}$ (all w/v) and $1 \%$ butyric acid $(\mathrm{v} / \mathrm{v})$, as in our previous study. ${ }^{3}$ The bacterial mass was washed with physiological saline and suspended into three media preparations. One of the media contained the ingredients stated above, while the second and third media lacked butyric acid and physiological saline, respectively.

From each of the three media, $10 \mu \mathrm{l}$ of the suspension was spotted on a Tosa Washi paper $(9 \mathrm{~mm} \phi$; Kikuron Ltd., Japan) and dried at $5^{\circ} \mathrm{C}$, which served as an immobilization membrane. The membrane was stored at $5^{\circ} \mathrm{C}$ before use.

\section{Microbial electrode}

The microbial electrode comprised an immobilized microbial membrane, attached to a Teflon membrane, and an oxygen electrode (Denki Kagaku Keiki Co.). The microbial membrane was fixed to the oxygen electrode by a dialysis membrane of a cellulose tubing
(Sigma Chemicals Co.), capable of retaining 90 - 99\% of cytochrome $c$ (MW 12400) with 24 h. 3,4

\section{Raw milk samples}

Fresh-milk samples were obtained from dairy farms in Kochi Prefecture, Japan, between September and October 1992. The samples were preserved at $1^{\circ} \mathrm{C}$ for $24-36 \mathrm{~h}$ prior to the analyses.

The total microbial load of the milk samples was determined by a direct microscopic count (Bleed method). ${ }^{5} \quad$ Raw-milk samples containing fewer microorganisms than $10^{5} / \mathrm{ml}$ were all expressed as $10^{5} / \mathrm{ml}$. The lipase activity was assessed by a fluorometric assay method $^{6}$, using 4-methylumbelliferyl heptanoate (Sigma Chemicals Co.) as the substrate.

\section{FIA system}

A schematic diagram of the flow system is given in Fig. 1. A potassium phosphate buffer (0.2 M, pH 7.0) served as the carrier solution. Sample solutions $(20 \mu \mathrm{l})$ were injected into the carrier solution with a six-way valve (Rheodyne Model 9125), and then pumped through a mixing coil ( $0.8 \mathrm{~mm}$ i.d., $60 \mathrm{~cm}$ long) and transported to a flow-through cell (Denki Kagaku Keiki Co., FLC-41) equipped with a microbial electrode. The flow rate was set at $1.0 \mathrm{ml} / \mathrm{min}$. The measurements were carried out at $30^{\circ} \mathrm{C}$ and the peak height was recorded as the electrode response. The milk samples were directly injected into

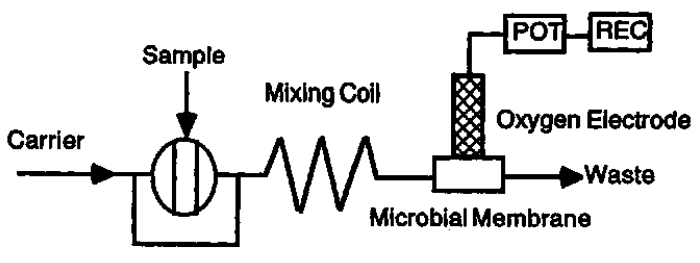

Fig. 1 Schematic diagram of the flow injection analysis system. POT, potentiostat; REC, recorder. 
the system without dilution. The concentration of the short-chain fatty acids in the milk samples was expressed as the concentration equivalent to butyric acid, using a calibration curve for butyric acid. The immobilization conditions of Arthrobacter nicotiana were optimized by a comparison of the response of $2.80 \mathrm{mM}$ butyric acid, which was the highest for linearity.

\section{Results and Discussion}

\section{Immobilization method of the microorganism}

In our previous paper, the microorganisms were immobilized in a polyvinyl alcohol membrane (PVA). ${ }^{3,4}$ However, this PVA membrane easily shrank upon contact with water; it was therefore not convenient for routine applications. The present study was thus conducted as an alternative method to overcome this disadvantage.

Tosa Washi, a special Japanese paper, was used as a membrane for the microorganisms and showed superior holding properties of the cell suspension and a suitable mechanical strength. Due to its large pores, the paper allowed unrestricted diffusion of oxygen when fixed on the Teflon membrane of an oxygen electrode. The composition of the solution in which the microorganisms were suspended (see Experimental) and the cell concentration $\left(0-4 \mathrm{mg} / \mathrm{cm}^{2}\right)$ spotted onto the paper affected the sensor response as well as the stability during storage. The optimum immobilization conditions of the microorganism were realized in a culture medium without butyric acid, and at a cell concentration of $4 \mathrm{mg} / \mathrm{cm}^{2}$. The immobilized microbial membrane was stable for at least two weeks under refrigerated conditions, which was comparatively longer than for the PVA membrane. ${ }^{3}$ The sampling frequency of the microbial sensor was about 15 samples/h. The detected concentration of short-chain fatty acids in the tested samples was linearly correlated to the response for standard butyric acid at concentration levels of between 0.11 and $2.80 \mathrm{mM}$. These sensor responses were comparable to those of a previously described sensor system.,

\section{Application of the microbial sensor to the evaluation of milk quality}

The microbial count is an important measure which shows the suitability of raw-milk handling, and is one of the most essential items in milk quality control. ${ }^{7}$ The growth of microorganisms in milk is known to easily produce off-flavors, including a rancid flavor. ${ }^{2}$ Since the rancid flavor is caused by the liberation of short-chain fatty acids, the relationship between the microbial count of the raw-milk samples and the concentration of shortchain fatty acids was examined using the microbial sensor (Fig. 2). The concentration of short-chain fatty acids showed a positive linear trend with the bacterial count in seventeen of the twenty samples assessed. The three odd samples had a bacterial count of $10^{5} / \mathrm{ml}$, and gave higher values for the short-chain fatty acids than

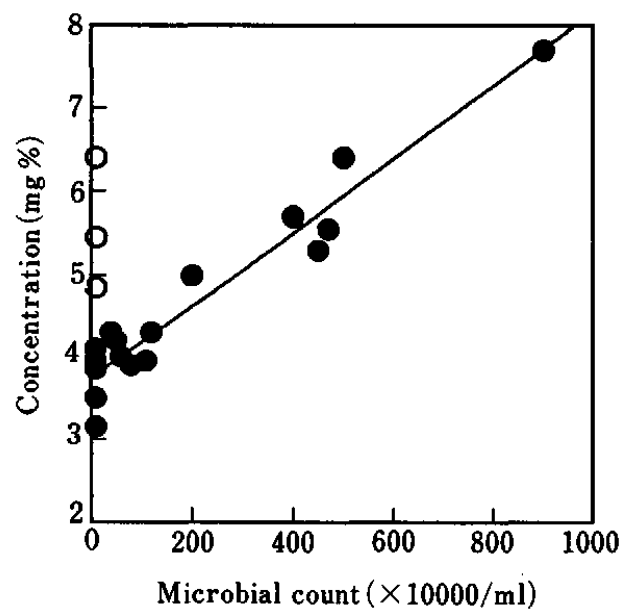

Fig. 2 Relationship between the microbial count and the concentration of short-chain fatty acids in raw-milk samples. The regression line was made, except for three samples $(O)$ containing fewer microorganisms than $10^{5} / \mathrm{ml}$.

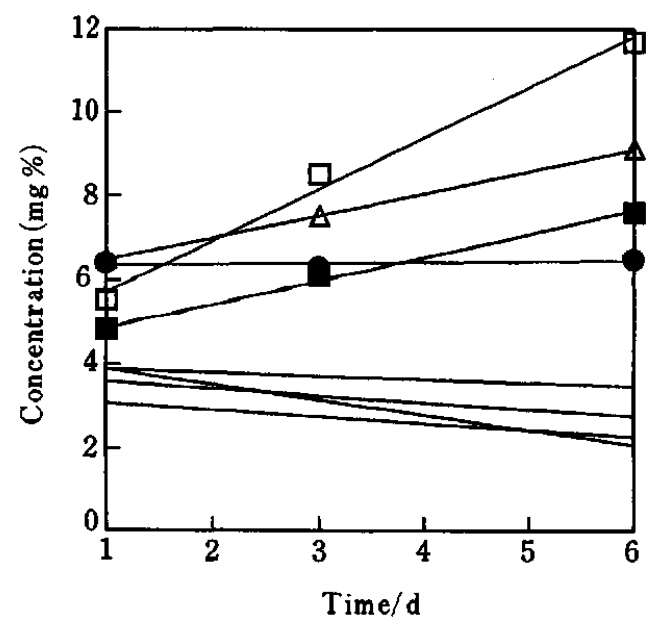

Fig. 3 Changes in the concentration of short-chain fatty acids in raw-milk samples during storage at $1^{\circ} \mathrm{C}$. The three samples that showed a lower microbial count than $10^{5} / \mathrm{ml}$ and a higher concentration of short-chain fatty acids in Fig. 2 are illustrated by $\square, \square$, and $\bigcirc$, respectively. The sample that showed a microbial count of $5.3 \times 10^{6} / \mathrm{ml}$ is illustrated by $\Delta$. The samples without an illustration symbol show a lower microbial count than $10^{5} / \mathrm{ml}$, and a lower concentration of short-chain fatty acids.

those with higher counts. The changes in short-chain fatty acids content among the eight selected milk samples during storage at $1^{\circ} \mathrm{C}$ are represented in Fig. 3. The samples having initial bacterial loads of less than $10^{5} / \mathrm{ml}$ showed a declining trend in the short-chain fatty acid concentration with increasing storage time. An interesting result was noted in the three odd samples shown in Fig. 2. These samples showed a remarkable or slight increase in the short-chain fatty acids concen- 
tration for prolonged storage, in a similar manner to those samples with high initial microbial counts. This behavior was characteristic of the so-called "spontaneous lipolysis milk" which may be produced by $2-22 \%$ of the cows in a given herd, and undergoes a hastened lipolysis, even at low initial levels of the microbial count. ${ }^{8}$ The concentration of short-chain fatty acids in raw milk after $24-36 \mathrm{~h}$ of milking is thought to depend on the initial lipolytic activity in the milk. ${ }^{9}$ However, no significant linear relationship between the short-chain fatty acids concentration and the lipolytic activity was established in this study. Milk lipolysis is due to a combination of different enzymes, as previously indicated. ${ }^{10}$ The 4methylumbelliferyl heptanoate selected as the substrate in this experiment may not be suitable for the lipolytic enzyme responsible for the activity.

The result of this study showed that the microbial sensor gave a rapid and reliable response to varying concentrations of short-chain fatty acids in raw milk, and that the response is related to the microbial count in milk. The present microbial sensor has sufficient sensitivity to detect a milk sample with a microbial counts greater than $4 \times 10^{6} / \mathrm{ml}$ (Fig. 2) and also "spontaneous lipolysis milk". Since mastitis milk, one of the typical abnormal milks, has also been implicated in spontaneous lipolysis milk $^{10-12}$, this result suggests that the microbial sensor might be applicable to detect mastitis milk. The present microbial sensor may be a valuable tool for determining short-chain fatty acids in raw milk, as well as changes during storage.

We express our sincere thanks to $\mathrm{Mr}$. Seishi Nozaki (Himawari Nyugyo Co.) for the raw-milk samples and microbial counting by the Bleed method, and $\mathrm{Mr}$. Simon $\mathrm{M}$. Njoroge for his assistance in preparing the manuscript. We also thank Prof. Dr. Rolf D. Schmid, Gesellschaft für Biotechnologische Forschung (Braunschweig, FRG), for providing us with Arthrobacter nicotiana (DSM No. 6707).

\section{References}

1. S. Kuzdzal-Sovoie, Int. Dairy Fed. Bull. Doc., 118, 53 (1980).

2. P. Walstra and R. Jenness, "Dairy Chemistry and Physics," Wiley, New York, 1984.

3. H. Ukeda, G. Wagner, U. Bilitewski and R. D. Schmid, J. Agric. Food Chem., 40, 4342 (1992).

4. H. Ukeda, G. Wagner, G. Weis, M. Miller, H. Klostermeyer and R. D. Schmid, Z. Lebensm. Unters. Forsch., 195, 1 (1992).

5. Y. Tsugo and K. Yamauchi, "Gyunyu no Kagaku (Chemistry of Milk, in Japanese)", Chikyusha, Tokyo, 1975.

6. G. G. Guilbault, M. H. Sadar and A. Arcenaux, Anal. Lett., 1, 551 (1963).

7. T. Doi, M. Kanzaki, H. Nakanuma, M. Shibuya and K. Matsumoto, Nippon Shokuhin Kogyo Gakkaishi, 39, 135 (1992).

8. D. P. Schwartz, "Fundamentals of Dairy Chemistry", W. Johnson, Acford, New York, 1977.

9. A. W. Shelly, H. C. Deeth and I. C. MacRae, J. Microbiol. Methods, 6, 123 (1987).

10. C. H. Fitz-Gerald, H. C. Deeth and B. J. Kitchen, J. Dairy Res., 48, 253 (1981).

11. R. Gudding, J. Food Prot., 45, 1143 (1982).

12. F. Atroshi, A. Rizzo, T. Oesterman and J. Parantainen, $J$. Vet. Med., A36, 321 (1989). 